\title{
Individual characteristics and career exploration in adolescence
}

MARIA DO CÉU TAVEIRA

Institute of Education and Psychology, University of Minho, Campus de Gualtar, 4700 Braga, Portugal

\section{CAROLINA SILVA}

Institute of Biomedical Sciences Abel Salazar, University of Porto, Largo Prof. Abel Salazar 2, 4050 Porto, Portugal

\section{MARIA LUÍSA RODRÍGUEZ}

Division of Educational Sciences, University of Barcelona, Campus de la Vall d'Hebron, Passeig de la Vall d'Hebron 171, 08035 Barcelona, Spain

\section{JOSÉ MAIA}

Faculty of Sports Sciences and Physical Education, University of Porto, Rua D. Manuel II, 4050 Porto, Portugal

ABSTRACT The effects of gender, age and school grade on several career exploration dimensions measured by the Career Exploration Survey were investigated. Subjects were high school students facing an imminent career decision. Regression analyses indicated that sex and grade-level were the most significant and prevailing individual characteristics related to the adolescents' career exploration behaviours, reactions and beliefs. Implications for career exploration interventions are discussed.

\section{Introduction}

A large and growing body of literature published over the past two decades has demonstrated the importance of career exploration in the career development and decision processes (e.g. Blustein, 1990; Phillips, 1992; Stumpf et al., 1983; Super, 1990) and has legitimated its role in career intervention (cf. Brown \& Brooks, 1991; Spokane, 1991; Zunker, 1994). Career exploration has been conceptualised as those purposeful activities, directed toward enhancing knowledge of the self and the external environment, that individuals engage in to foster progress in career development (Berlyne, 1965; Blustein, 1990, 1992; Jordaan, 1963; Stumpf et al., 1983). 
Originally, in career development theory, career exploration was assumed to occur during the late years of adolescence (Ginzberg et al., 1951; Super, 1957, 1963; Tiedeman \& O'Hara, 1963). Subsequently, however, it was conceived as a dynamic process that occurs at all ages and stages of development, whenever a decisional cycle begins (Tiedeman, 1961), although it may be most prominent during late adolescence and early adulthood Jordaan, 1963; Super 1990).

Despite the consensus about the importance of understanding how career exploration proceeds along the entire life span, empircal research has been based mainly on young adults, generally college and undergraduate students who are trying to implement specific career choices (cf. Blustein, 1990, 1995). Since subsequent exploration activity is contingent on past exploratory activity, including the nature of the exploratory process as well as the reactions to past exploration, and beliefs regarding the utility of furure exploration (cf. Stumpf et al., 1983), further research on the nature and dynamics of career exploration in the earlier stages of career development is needed.

It has also been argued that career exploration should be understood with reference to the particular contexts in which it is occurring, including one's immediate social influences (e.g. family, school and community) and broader social influences such as the educational and vocational opportunity structure of a given culture (Blustein, 1995; Grotevant, 1987; Grotevant \& Cooper, 1985, 1988; Richardson, 1993; Vondracek et al., 1986). According to this contextual view, contemporary as well as historical factors relating to familial, social and economic systems are considered to affect individuals throughout their life-span and may determine, along with intrapersonal and intrapsychic factors, individual differences in the process of career exploration (Blustein, 1995, p. 14).

Existing empirical research indicates that individuals may vary in their exploratory activity (extent and nature) as a function of individual and contextual factors (cf. Blustein, 1990, 1995; Jordaan, 1963; Strumpf et al., 1983). Moreover, although fostering intensive self and environment exploration has been conceived as an important vehicle for promoting gains in career intervention, there is an increasing awareness that individual differences should be considered when assisting clients in career exploration. Yet, despite the number of references in the vocational psychology literature supporting the benefits of career exploration, empirical evidence on the favourable outcomes of exploratory activity is still fairly inconclusive (Jepsen, 1984; Blustein, 1990).

Accordingly, additional research is needed to understand better the nature of career exploration and the factors that facilitate or impede it, as well as the outcomes of exploration. The results of such a line of research may have important theoretical implications as well as practical interest, particularly if one considers that career intervention should enhance the mobilisation of systematic constructive exploration behaviours in order to promote the clients' success in coping with career situations (Spokane, 1991, pp. 56-57). With this in mind, the present study was designed to analyse the possible effects of gender, grade-level and age on the career exploration atritudes and behaviours of young adolescents facing imminent career decisions. 


\section{Methods}

\section{Subjects}

The sample of this study was composed of 1,400 Portuguese students, 700 of 9 th grade and 700 of 12 th grade, from 10 semi-urban and urban north-western secondary schools. The 9 th and 12 th graders ranged in age from 13 to 18 years $(M=14.8$, $S D=1.04)$, and from 16 to 22 years $(M=17.9, S D=1.12)$, respectively. The 770 females and the 630 males averaged 16 years in age $(S D=1.89)$. Only $15.2 \%$ $(\mathrm{N}=213)$ of the students had previously received career guidance.

\section{Procedure and instruments}

Subjects completed an information form (requesting age, sex and grade) and the Career Exploration Survey (CES). The administration of the instruments occurred at the beginning of the school year, from October to December 1993, just before the start of school career interventions, in order to avoid possible effects of this experience on the CES responses.

The CES (Stumpf et al., 1983) is a multidimensional self-administered scale with 62 items using a Likert-type response format, designed to assess six beliefs about exploration, seven dimensions of the career exploration process, and three reactions to exploration [1]. The definitions of these 16 separate facets of career exploration are presented in Table 1. The evidence for the multidimensionality, reliability and validity of the CES was assessed by Stumpf et al. (1983) on four studies with college students and professionals. These provided evidence consistent with theory for the use of the instrument in career research.

More recently, and because the CES was initially developed for young adults, minor modifications of the scale were introduced by Blustein (1988) in order to adapt its content to adolescents. Specifically, four new items were added to the original five-item self-exploration scale to provide a more complete assessment of the adolescents' self-exploratory activities; one additional item regarding exploring or deciding on academic major was added to each of the two Stress scales; and a new four-item sub-scale measuring career decision-making instrumentally was introduced. Additional satisfactory reliability data were obtained and reported for these revised and new scales, in a recent series of research articles devoted to the career exploration process and correlates (e.g. Blustein, 1988, 1989a, 1989b; Blustein et al., 1989a; Blustein \& Phillips, 1988).

This version of the CES was translated into Portuguese by a bilingual individual, and then evaluated by career guidance specialists; a reverse translation of it was approved by David Blustein. The translated version of CES was administered to a screening sample of 9 th and 12 th graders $(N=170)$, followed by interviewing in a small group of subjects $(N=30)$, in order to determine the adequacy of the item content and response format. With the same goal, the responses of the screening sample were subjected to an item analysis. The results of these procedures led to the decision to delete several items from the scale, due to lack of item reliability and validity and to content redundancy or evident cultural inadequacy [2]. The refined version of the CES included 53 items, representing the following scales: Employ- 
TABLE 1. Dimensions of career exploration

Labour market

BELIEFS

- Employment Outlook. How favourable the employment possibilities look in one's career area.

- Cenainty of Career Exploration Outcomes. The degree of certainty one feels that he/she will attain a desired position.

Instrumentality

- External Search Instrumentality. The probability that exploring the environment for career opportunities will lead to obtaining career goals.

- Intemal Search Instrumentality. The probability that reflection on past career behaviour and retrospection will lead to obtaining career goals.

- Method Search Instrumentality. The probability that being intended and systematic in one's career exploration will lead to obtaining career goals.

Preference

- Imporance of Obraining Preferred Position. The degree of importance placed on obtaining one's career preference.

Where

\section{EXPLORATION PROCESS}

- Environment Exploration. The extent of career exploration regarding occupations, jobs, and organisations within the last 3 months.

- Self-Exploration. The extent of career exploration involving self-assessment and retrospection within the last 3 months.

How

- Intended-Systematic Exploration. The extent to which one acquires information on oneself and the environment in an intended or systematic manner.

How much

- Frequency. The average number of times per week that one seeks career information over a 2-month period.

- Amount of Information. The amount of information acquired on occupations, jobs, organisations, and oneself.

Directness

- Number of Occupations Considered The number of different occupational areas on which one is acquiring information.

- Focus. How sure one feels in hisher preference for a particular occupation, job, and organisation.

Affect

$$
\text { REACTIONS TO EXPLORATION }
$$

- Satisfaction with Information. The satisfaction one feels with the information obtained regarding occupations, jobs, organisations relative to one's interests, abilities and needs. Stress

- Explorational Stress. The amount of undesirable stress, relative to other significant life-events, with which one has to contend, felt as a function of the career exploration process.

- Decisional Stress. The amount of undesirable stress, relative to other significant life-events, with which one has to contend, felt as a function of the career decision-making process.

Source: Stumpf et al. (1983).

ment Outlook (EO), Certainty of Career Exploration Outcomes (CEO), External Instrumentality (EI), Internal Instrumentality (II), Method Instrumentality (MI), Decisional Instrumentality (DI), Importance of Preferred Position (IMP), Environment-Exploration (EE), Self-Exploration (SE), Amount of Information (AI), Number of Occupations Considered (NOC), Intended-Systematic Exploration (ISE), Satisfaction with Information (SI), Explorational Stress (ES) and Decisional Stress (DS). 
With the exception of the single-item NOC, the item pool of the CES was factor-analysed for construct validity, using the exploratory method of Principal Component Analysis. The findings indicated that a 12-factor model best described the data. This model included 10 simple factors representing the EO, CEO, EI, $\Pi$, IMP, SE, EE, ISE, SE and DS constructs. The two remaining factors were more complex and comprised $\mathrm{MI}$ and DI items, and $\mathrm{AI}$ and SI items, respectively.

The factor structure was tested in relation to gender and grade-level. The results did not vary in relation to gender. However, only seven of the 12 factors extracted were the same for both grade-levels. Nevertheless, the results of second higher-order analysis revealed that the dimensional structure of CES could be defined by a reduced three-factor model, identical for both grades.

The factorial invariance of the dimensional patterns derived from the exploratory factor analyses was then tested in a confirmatory factor analysis using LISREL VII Jöreskog \& Sörbom, 1989), following the model proposed by Jöreskog $(1969,1977)$. Several models were tested for each of the career exploration components: beliefs, process, and reactions [3]. The results of these analyses revealed that a five-factor model (EO, CEO, DI + MI + EI, II, IMP) for the beliefs component, a four-factor model for the process component (AI, EE, SE, ISE), and a three-factor model for the reactions component (SI, ES, DS) were the most adequate models to represent the data. These models did not vary across gender and grade-level groups. As expected, given the large sample size involved, in spite of the adequacy of the final models, the $\chi^{2}$ goodness of fit tests were significant $(p<0.05)$. The values of the remaining indices examined were within the acceptable range of values for evaluating adequacy of the fit (e.g. the GFI and AGFI indices were all greater than 0.90 , and the RSMR indices were, for all models, greater or equal to 0.05 ). The results obtained generally supported the multidimensionality of the CES, indicating that several cognitive motivational as well as behavioural dimensions of the career exploration process can be measured reliably with the instrument in future research with adolescents. The findings also suggest that the adolescents in this study have a more parsimonious representation of the exploration beliefs component than would be expected in the light of the dimensional model underlying the CES [4].

\section{Data analysis}

Items included in each career exploration scale were added, using unit weights. Since each scale had a different number of items and also differences in the range of score values, the sum of scores for each dimension were transformed linearly to a $0-100 \%$ scale, in order to make possible comparisons between the dimensions.

Regression models were used to study the patterns of variation of the CES dimensions with sex, grade and age. Sex and grade were included in the models as dummy variables ( 1 for fermales and 12th grade; zero for males and 9th grade) (Searle, 1971). These models included the main effects of sex and grade and age as a covariate. First-order interactions were also considered, but only included in the model if their effect, adjusted for the variables already in the model, was significant at the 0.05 level. To test the adequacy of a given model for the estimation of the 


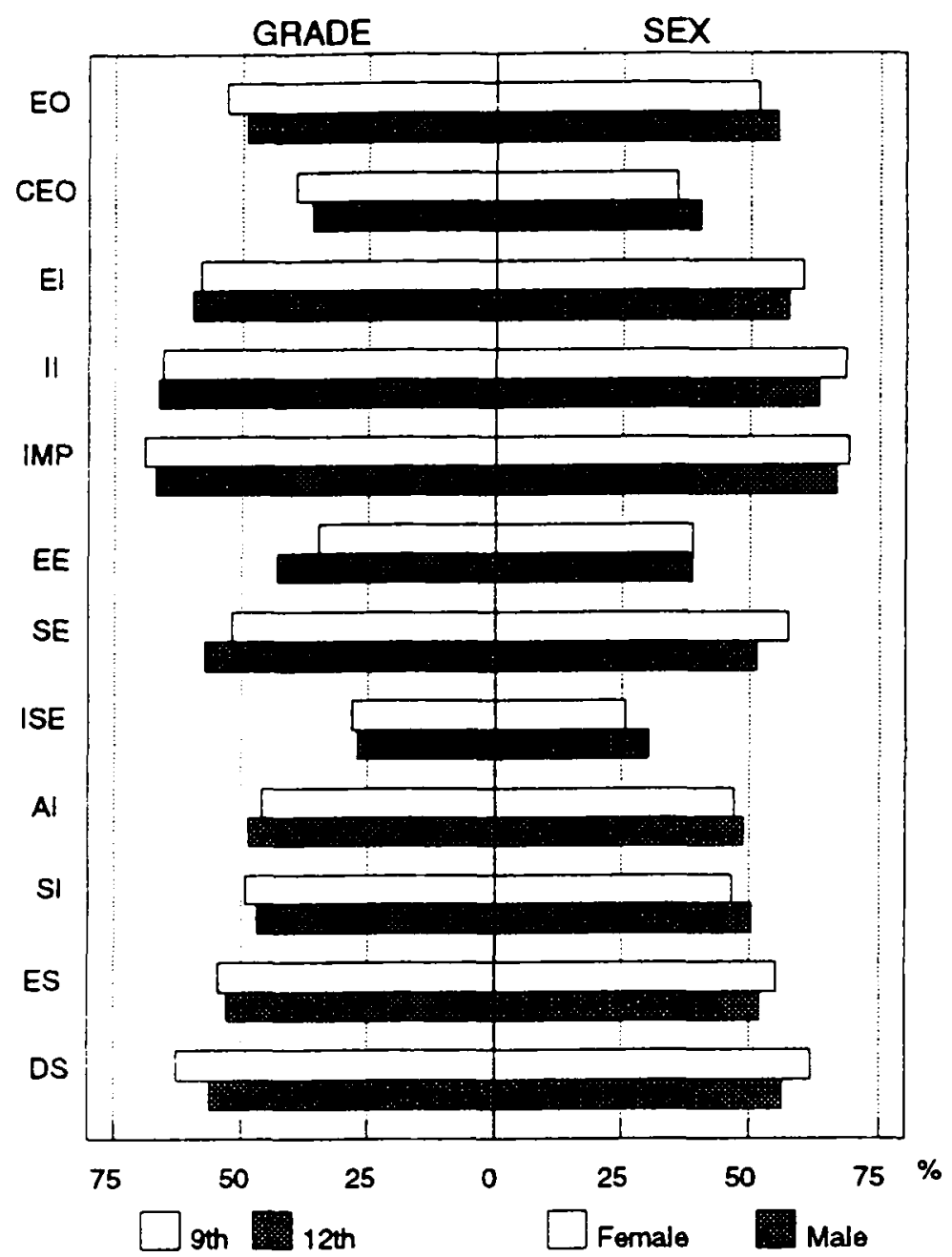

FIG. 1 Total sample means and standard deviations for CES dimensions.

expected effects of the variables, a thorough inspection of univariate and multivariate outliers was performed. As a result, the number of subjects analysed in the several models is not the same, varying from 1,390 to 1,358 . Ten cases corresponding to multivariate outliers were excluded in all analyses, as judged by the Mahalanobis distance to the centroid of all cases, distributed as a chi-square variable with the degrees of freedom equal to the number of independent variables (Tabachnick \& Fidell, 1989). The BMDP/DYNAMIC 7.0/1993 (Dixon, 1992) software was used for these analyses.

\section{Results}

The total sample means and standard deviation for CES dimensions are presented in Figure 1. Seven exploration dimensions mean values are above the mid-point of the scale (EO, EI, II IMP, SE, ES, DS) and five are below (CEO, EE, ISE, AI, SI). These results indicate that, in general, the adolescents in this study reported fairly 
positive beliefs about career exploration, scored low in the career exploration process dimensions, and revealed low satisfaction and high stress in reactions to exploration.

The results of the hierarchical multiple regression analyses designed to explore the effects of gender, grade and age on the CES dimensions are presented in Table 2. Although no a priori hypotheses were formulated, several significant mean differences in career exploration were found for the three factors considered.

Specifically, for the same age and grade, girls tended to report less favourable Employment Outlook, and less Certainty of Career Exploration Outcomes, than boys. Moreover, either for girls or boys, the score for Employment Outlook decreased on average by $6.27 \%$ in the 12 th grade.

Twelfth graders felt that external search was more instrumental than 9th graders. Within the same grade, females reported higher External Instrumentality than their male peers, and scores tended to decrease with age for both sexes. As opposed to this, internal instrumentality scores did not vary significantly with age or grade, although for the same age and grade, girls reported considerably higher internal instrumentality than boys (5.02\% more on average). Importance of Obtaining a Preferred Position did not vary across gender, grade or age.

Regarding the process of exploration, the 12th-grade students scored significantly higher Environment Exploration than those in the 9 th grade, on average $9.77 \%$ more. Self-Exploration, besides being more frequent in the 12 th grade than in the 9 th grade, was considerably higher in girls than in boys. For the Intended-Systematic Exploration dimension, a significant interaction was found between grade and age (coefficient $=3.89[1.27], F[1,1353]=9.4, p<0.01$ ), as well as a significant main effect of gender (see Figure 2(a)). Girls reported significantly less IntendedSystematic Exploration than boys, and while in the 9th grade this method of exploration decreased with age, in the 12th grade the opposite pattern of variation with age was found. Amount of Information did not vary across gender, grade or age.

Finally, regarding the reactions to exploratory behaviour, the results indicate that regardless of age and grade, girls seemed to be less satisfied with the information obtained and reported higher levels of explorational and decisional stress than boys. Furthermore, for Decisional Stress, there was a significant interaction between grade and gender (coefficient $=-5.74[2.54], F[1,1385]=5.1, p<0.05>$, and a significant main effect of age (see Figure 2(b)). Thus, despite the grade, Decisional Stress decreased with age, being higher in girls than in boys. Nevertheless, for the 9 th grade the difference in the mean score for Decisional Stress of girls and boys is significantly higher than that for the 12 th grade.

\section{Discussion}

The present study was designed to examine the career exploration of high school students facing an imminent career decision, and to explore whether gender, grade and age could explain differences in these adolescents' exploratory behaviours and atritudes.

The results reveal that, although the adolescents in this study have relatively 
96 Maria do Céu Taveira et al.

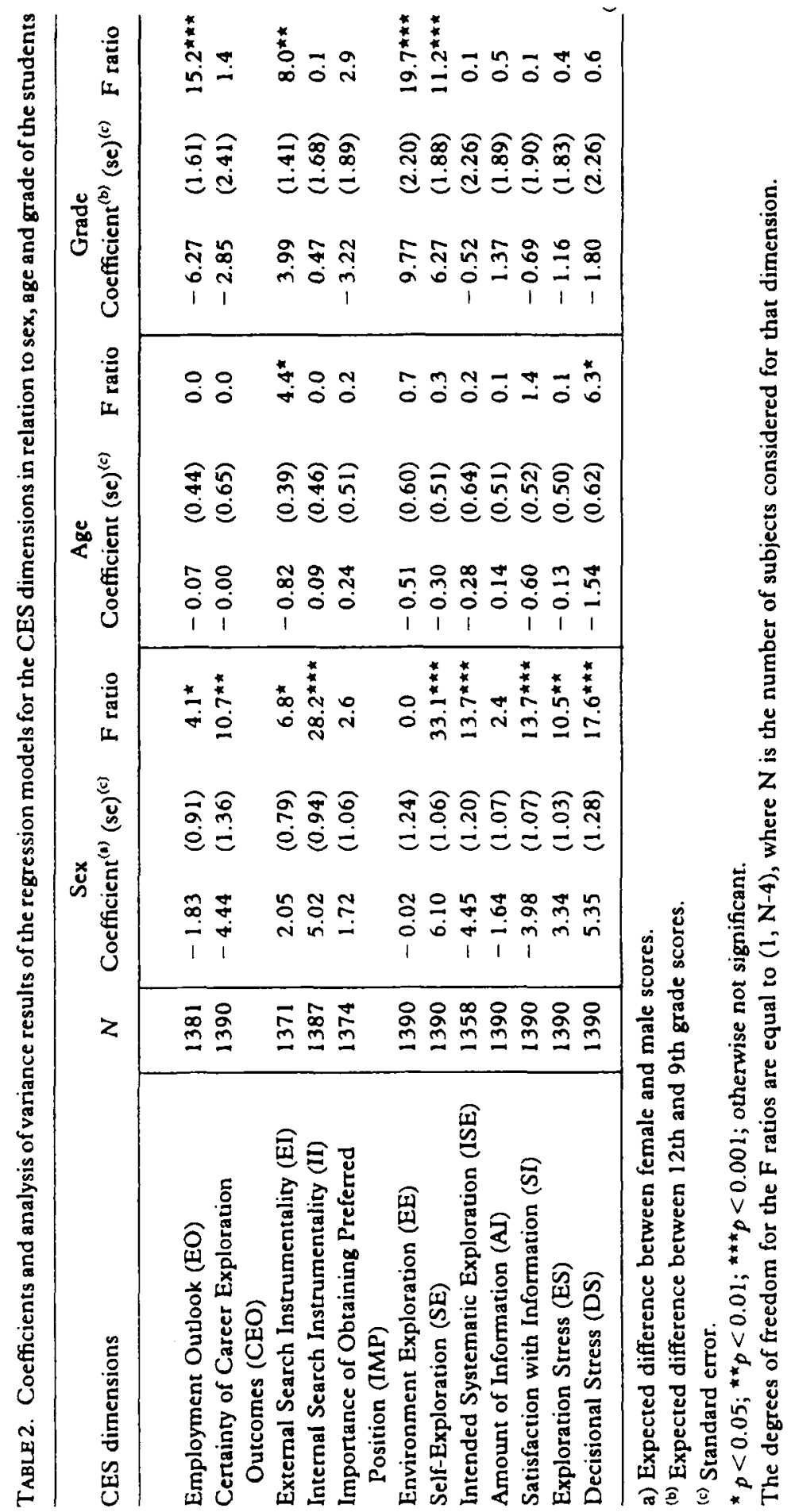




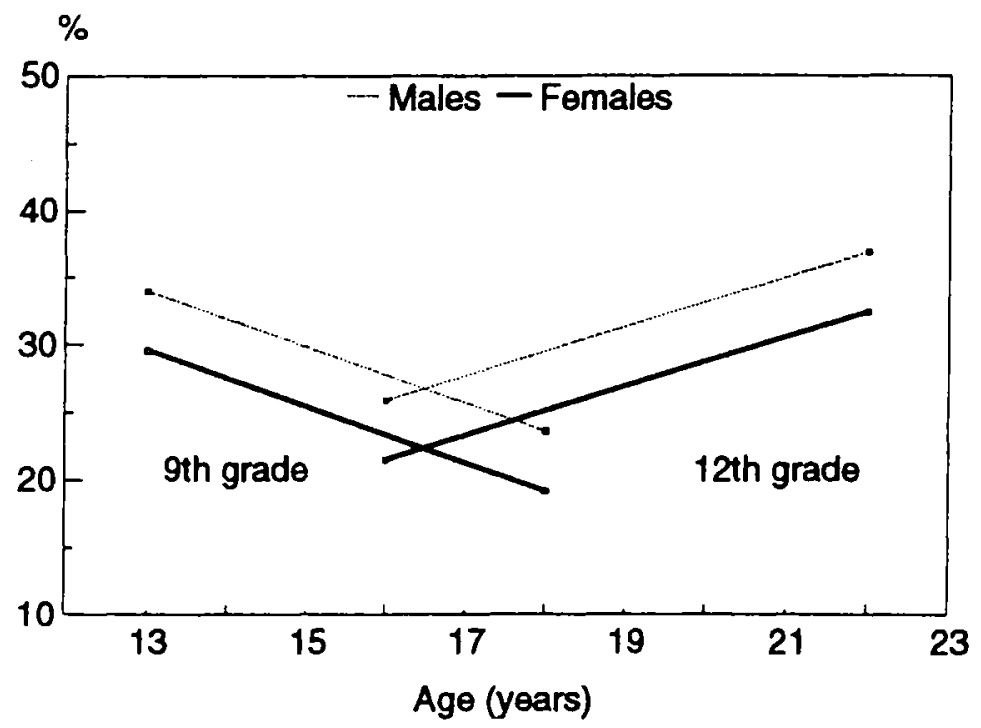

Fig. 2(a) Intended-Systematic Exploration dimension: a significant interaction between grade and age, and a significant main effect of gender.

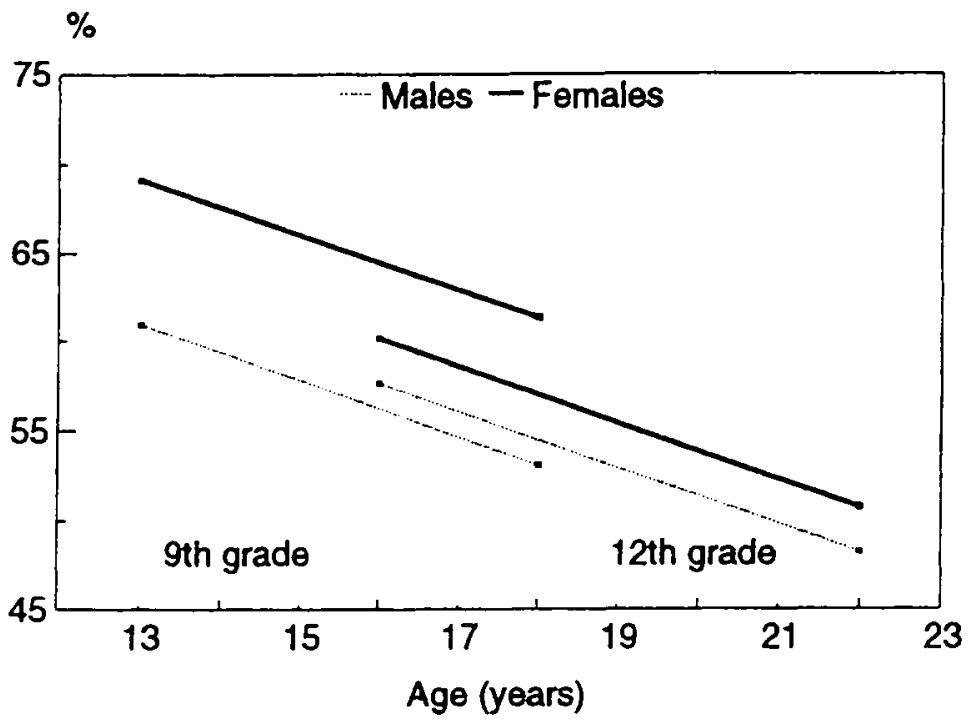

FIG. 2(b) Decisional stress-a significant interaction between grade and gender, and a significant main effect of age.

favourable perceptions of the labour market in their chosen career area, and feel it is important to them to obtain their preferred position, they do not have much certainty of attaining it. Moreover, these adolescents believe in the instrumental value of both self- and environment-exploration activities, though they have been engaged mainly in self-exploration. Low scores were found for Environment Exploration and also for Amount of Information, Systematic-Intended Exploration, and Satisfaction with Information. Furthermore, the subjects reported the experience of fairly high levels of stress associated with career exploration and decision-making activities. 
These results reveal that the adolescents of this study have explored themselves, feel that internal and external exploration is worthwhile, have established some career preferences, and have yet to explore their environment systematically. Considering these findings, it would seem important to design interventions to help these students develop competence in career exploration which would facilitate their future career exploration processes. The understanding of the dynamics of the career exploration process in adolescence may contribute to the development of such interventions.

For example, taking into consideration that perceptions about career opportunities and expectations of attaining career goals are conceived as important cognitivemotivational factors of career exploration (cf. Hackett \& Betz, 1981; Lent et al., 1994; Mitchell \& Krumboltz, 1990; Spokane, 1991; Stumpf et al., 1983), it is possible that, for the adolescents studied, the existence of negative career outcome expectations may function as an internalised barrier to constructive and persistent involvement in career exploration activities. Nevertheless, the results of this study also show that students feel some sense of imminence regarding career development tasks, believe that exploration is worthwhile, and have already initiated some career exploration activities. That is, overall, these results suggest that these adolescents may be predisposed to engage in career exploration. In fact, according to theory and previous research, conditions such as perceived access to career options (Blustein, 1990), the experience of uncertainty (Berlyne, 1960, 1963, 1965; Jordaan, 1963), the attribution of instrumental value to career exploration in relation to career decision-making and vocational adjustment objectives (Blustein, 1989b; Stumpf et al., 1983; Stumpf \& Lockhart, 1987), and contexts in which individuals experience some degree of exploratory stress (Blustein \& Phillips, 1988), are good predictors of involvement in career exploration.

The findings are consistent with theory and research suggesting that, in general, in middle to late adolescence, individuals tend to be in the early phase of the commitment process to a career choice, and concomitantly in the initial stages of career exploration (Blustein, 1988; Blustein et al., 1989b; De Fleur \& Menke, 1975; Grotevant \& Durrett, 1980; Harren, 1979; Jordaan, 1974; Super, 1957; Tiedeman \& O'Hara, 1963). However, as could be expected, given that most of the adolescents studied seem to be in the early phase of their vocational planning, the results also suggest that the students may need assistance in knowing where and how to explore more effectively for career purposes. The findings show that these adolescents are not very satisfied with the career information obtained in their exploration activities. This could indicate lack of directness in their career exploration, or a lack of adequate career exploration resources and assistance in their educational environments.

Furthermore, the results show that students have been engaged in self-exploratory activity but exhibit very low environment-exploration as well as low levels of intended-systematic exploration. Although it has been argued that self-exploration plays a central role in career development (e.g. Blustein, 1990; Jordaan, 1963; Stumpf et al., 1983; Super, 1990), it is also recognised that acquiring an understanding of relevant aspects of educational and occupational environments is an import- 
ant component of that process in late adolescence (cf. Holland, 1985; Jordaan, 1963; Stumpf et al., 1983; Super, 1990). Moreover, progress in career decisionmaking has been proved to be associated mainly with systematic exploratory activity (Blustein 1988; 1990; Blustein et al., 1994; Super, 1990). In addition, some forms of exploration such as consulting friends, teachers and family members may be used more frequently by the adolescents because of their availability rather than because the young people sense they would foster more effective exploratory activity (e.g. Greenhaus et al., 1983; Grotevant \& Durrett, 1980; Taveira et al., 1994).

Overall, these results suggest that the students are in the early phases of career exploration and could benefit from career counselling assistance. When sex, grade and age effects are taken into consideration, some specific needs are highlighted which could be considered in the design and development of career intervention strategies.

Recent empirical work suggests that gender and age are related to some of the career exploration dimensions under study (Blustein, 1988, 1989a, 1989b; Blustein \& Phillips, 1988; Stumpf et al., 1983; Stumpf \& Lockhart, 1987). In the present study, multiple regression analyses revealed that gender did correlate significantly with some career exploration dimensions. High school girls tend to report less favourable career market perceptions and more negative career exploration outcome expectations, as well as more contextual stress, than their male peers. Moreover, girls were less satisfied with the information obtained than boys, and felt that self-exploration was more instrumental than did their peer males.

From a social cognitive career perspective, outcome expectations may be a result of self-efficacy perceptions which, in turn, are influenced by early and ongoing individual and contextual factors that can act as resources or as barriers (cf. Hackett \& Byars, 1996; Lent et al., 1994; Lent \& Brown, 1986). One such factor that may be relevant is gender. Existing career theory and research suggests that contextual factors such as gender-related barriers within the work opportunity structure (female segregation), and traditional sex-role socialisation (within home and school settings), along with other early and ongoing learning experiences, may circumscribe female career aspirations and achievement, and consequently the scope of female career exploration (e.g. Betz \& Fitzgerald, 1987; Farmer, 1985; Fitzgerald \& Betz, 1983; Gotffredson, 1981). Research on gender differences has also confirmed the assumption that individual factors such as women's career self-efficacy and career outcome expectations may be influenced by these contextual factors, and that this, in turn, may also limit the range of career options considered (cf. Betz \& Hackett, 1981; Lent et al., 1994; Brown \& Lent, 1996). Thus, as Brown \& Lent (1996) have recently noted, females may premarurely restrict the scope of their career exploration activity, based on inaccurate self-efficacy and outcome expectations, or both. Furthermore, if women perceive substantial barriers to pursue a career goal, they may be less likely to translate their interests into choices (ibid.).

Thus it is possible that academic leaming experiences and traditional sex-typed gender role socialisation (e.g. at home and in school settings) may have influenced the career self-efficacy perceptions of the females studied, which may explain their more negative career outcome expectations. Less favourable expectations about 
one's career goals attainment may function as a barrier to exploration action because it may lead to negative feelings (decrease in hope, increase in stress) which, in turn, affects one's motivation to action, specially if the importance of attaining that goal is high. Thus, girls from this study may need assistance in coping with low outcome expectations and perceived barriers, in order to prevent lack of engagement in career exploration and other career development planning activities. Since they substantially valued self-exploration, counsellors would benefit from beginning their intervention by helping the girls in self-assessment, within a social cognitive career approach. More specifically, challenging and supportive strategies could be used to help females to review their previous performance history in order to identify possible sources of low self-efficacy perceptions and inadequate causal attributions of performance; to enhance accurate self-evaluations and the acquisition of new success experiences; and to foster competence in career exploration. Self-exploration of females could also be enhanced by helping them to reflect on their interests, abilities, values and goals in relation to career information (for further suggestions, see Blustein, 1992; Chartrand \& Rose, 1996; Spokane, 1991).

This study also indicated that there were differences in career exploration atritudes and behaviours between the 9 th-grade and 12th-grade groups. Employment Outlook Perceptions, although favourable, were less positive in the 12th grade than in the 9 th grade. However, senior high school students felt that environment exploration was more instrumental, and had done more self- and environmental exploration, when compared with their junior high school peers. Although at the end of the school year, both 9 th and 12th graders have to make a similar career choice (pursuing studies or entering the job market), it could be expected that because 12th graders are in the phase of pre-implementation of more specific career choices than those finishing compulsory education, they may perceive more barriers (realistic or inaccurate) to accessing preferred career alternatives. The results also support the argument that as students advance from elementary to secondary school, they become more interested in specific occupational information and may be more inclined to engage in career exploration, in order to implement specific educational or vocational decisions (cf. Blustein, 1990).

Regarding age differences in career exploration, the results revealed that external instrumentality decreases with age, for both grade-levels and both sexes. Moreover, despite the fact that no differences were found in intended systematic exploration between 9 th and 12 th graders, the interaction found between grade and age indicates that this method of exploration tends to decrease with age in the 9 th grade, and to increase with age in the 12 th grade. For the 9 th grade, the results confirm previous findings with Portuguese high school students, indicating that older 9 th graders tend to have had more academic performance problems and to be significantly less 'intended' and systematic in their educational and career planning than the younger ones (Taveira et al., 1994). The increase of intended-systematic exploration with age, in the 12th grade, may be due to the fact that several of the older 12 th graders have already been engaged in more extra-curricular activities and work experiences, including part-time jobs, which favoured the responses obtained from the older 12 th graders in the intended-systematic scale of the CES. 
Finally, this study indicated that decisional stress levels tend to decrease with age in both sexes and both grade levels. However, an interaction between grade and sex was found in this dimension of exploration. Thus, 9th-grade girls tend to experience considerably higher levels of stress associated with decision activities than 12th-grade girls; while 9th-grade boys tend to experience relatively lower levels of decisional stress, when compared with their 12 th-grade peers. It is possible that because the older adolescents in this study are students with a poorer academic history, they use more passive and self-defeating psychological strategies to cope with their academic problems and career decisions, thereby reporting lower levels of anticipated stress in relation to educational or occupational choices. Both 9th-grade girls and 12th-grade boys seem to be less confident and more anxious with respect to career choices, which suggests that these two groups of students would benefit from interventions that prevent possible non-constructive attitudes and behaviours associated with those states (e.g. fear, inadequate cognitions and theories about career decision-making process, persistent indecision, dysfunctional anxiety, lack of persistence, lack of interest in exploration).

Consistent with previous findings with young adults, the results of this study indicate that it is important to consider individual characteristics in the study of career exploration in adolescence. Nevertheless, because no preceding research has been conducted using the particular group of subjects and variables of this study, comparisons between our results and previous research findings with US college students must be interpreted cautiously.

Overall, the results indicate that it is important to help adolescents to enhance their motivation and competence in career exploration. According to Blustein $(1990,1992)$, several specific goals and strategies can be derived from theory and research in career exploration, in order to develop appropriate career counselling intervention with adolescents. For example, interventions that are supportive and interactional and that specifically enhance clients' sense of competence in exploration would seem most appropriate in fostering exploration activity. Theory and research on career exploration motivational factors suggest that exploration is associated with an intrinsic motivational orientation (Blustein, 1988; Jordaan, 1963), and that adolescents would benefit from interventions that motivate active and self-determined exploration, since self-determination promotes the experience of competence and autonomy which, in turn, result in feelings of satisfaction.

In conclusion, the results of this study provide evidence that, although there are relevant new directions in theory and research on the process of career exploration, individual and contextual factors of career exploration need to be more fully studied and understood. Such knowledge can contribute to selecting more appropriate goals and actions in career interventions.

\section{Acknowledgements}

This study is par of a larger research project on Adolescents' Career Development, supported by grants from JNICT, PSI/436-92. The authors are grateful to Professor David Blustein for his helpful comments. 


\section{Notes}

[1] Five-point Likert scales are used for all items with the exceptions of the Explorational and Decisional stress scales, which use a seven-point scale, and the Frequency scale, which uses five categories.

[2] For example, for the groups under srudy, the term 'exploration' as well as the term 'career' was not understood, provoking some confusion. This led to the decision to use alternative terms in the scale. Moreover, many of the students under study were unfamiliar with and did not differentiate many of the terms defining the objects of exploration (e.g. occupations, jobs, organisations). In these situations, one single term was chosen. However, because the content of several items was defined in the scales only by the object of exploration, they became redundant and so were eliminated. Furthermore, the content of the items of the Focus and Frequency dimensions were found to be culturally inadequate, and the results of item analysis revealed a strong negative skewing in the distribution of the response values. Taking into consideration one or more of these reasons, the following items were not included in the final Portuguese version of the CES: items 4, 5 and 9 from the Satisfaction with Information scale; all the items of the Focus scale; item 17 from the Intended Systematic Exploration scale; items 19 and 22 from the Environment Exploration scale; item 24, 25, 26, 28 and 31 from the Self-Exploration scale; item 39 of the Frequency of Career Search Behaviour scale; and items 55 and 57 from the Importance of Obtaining Preferred Position scale.

[3] To evaluate the fit for the different models, four indices were examined, namely the chi-square index $\left(x^{2}\right)$, the ratio of chi-square to degrees of freedom ( $\left.x^{2} / \mathrm{d} f\right)$, the root mean square residual (RMSR), the Jorreskog-Sörbom goodness of fit index (GFI), and the adjusted goodness-of-fit index (AGFI).

[4] More specifically, the subjects did not differentiate the meaning represented by the indicators of the EI, DI and MI dimensions. Nevertheless, based on the source of information of the exploratory activities described in the instrumentality scales, the subjects differentiated internal instrumentality (II) from non-internal instrumentality (DI $+\mathrm{MI}+\mathrm{EI}$ ). For this reason, the $\mathrm{DI}+\mathrm{MI}+\mathrm{EI}$ factor was defined as External Instrumentality (EI). This indicates that the source of information was more salient for the students than the nature of the exploration activities in differentiating those exploration dimensions.

\section{References}

Berlyne, D.A. (1960). Conflict, Arousal, and Curiosity. New York: McGraw-Hill.

BERLYNE, D.A. (1963). Motivational problems raised by exploratory and epistemic behaviour. In S. Koch (Ed.), Psychology: a Study of a Science. New York; McGraw-Hill.

BERLYNE, D.A. (1965). Structure and Direcrion in Thinking. New York: Wiley.

Betz, N.E. \& Frtzgeraid, L.F. (1987). The Career Prychology of Women. San Diego, CA: Academic Press.

BETZ, N.E. \& HACKETT, G. (1981). The relationship of career-related self-efficacy expectations to perceived career options in college women and men. Journal of Counseling Psychology, 28, 394-440.

BLusten, D.L. (1988). The relationship between motivational processes and career exploration. foumal of Vocational Behavior, 32, 345-357.

BLUSTEN, D.L. (1989a). The role of goal instability and career self-efficacy in the career exploration process. Foumal of Vocational Behavior, 35, 194-203.

BLusten, D.L (1989b). The role of career exploration in the career decision making of college students. Foumal of College Student Development, 30, 11-117.

BLusTEN, D.L. (1990). Explorations of the career exploration literanure: current status and future directions. Invited address delivered at the American Educational Research Association Convention, Boston, MA, April.

BLLSTEIN, D.L. (1992). Applying current theory and research in career exploration to practice. Career Development Quarterly, 41, 174-184.

BLUSTEIN, D.L. (1995). A context-rich perspective of exploration across life roles. Paper presented at the Annual Convention of the American Psychological Association, August. 
BLUSTEN, D.L. \& PHIJIPS, S.D. (1988). Individual and contextual factors in career exploration. foumal of Vacational Behavior, 33, 203-216.

BLusteIN, D.L., Devents, L.E. \& KIDNEY, B.A. (1989a). Relationship between the identity formation process and career development. Foumal of Counseling Psychology, 36(2), 196-202.

BLUSTEN, D.L., EuLS, M.V. \& DEvenIS, L.E. (1989b). The development and validation of a twodimensional model of commitment to career choices problem. Foumal of Vocational Behavior, 35, 342-378.

Blusten, D.L., PAUring, M.L., DeMANTA, M.E. \& FAYE, M. (1994). Relation between exploratory and choice factors and decisional progress. Fournal of Vocasional Behavior, 44, 75-90.

Brown, D. \& Brooks, L. (1991). Career Counseling Techniques. Boston: Allyn \& Bacon.

BROWN, S.D. \& LENT, R.W. (1996). Applying social cognitive theory to career counselling. an introducion. Career Development Quarzerty, 44, 354-366.

CHARTRAND, J.M. \& ROSE, M.L. (1996). Career interventions for at-risk populations: incorporating social cognitive influences. Career Development Quarterty, 44, 341-352.

DE FLEUR, L.B. \& MENKE, B.A. (1975). Learning about the labour force: occupational knowledge among high school males. Sociology of Education, 48, 324-345.

Dxon, W.J. (Ed.). (1992). BMDP Statistical Software (Vols. 1-2). Los Angeles, CA: University of California Press.

FARMER, H.S. (1985). Model of career and achievement motivation for women and men. fournal of Counseling Psychology, 32, 363-390.

FITZGERAID, L.F. \& BETZ, N.E. (1983). Issues in the vocational psychology of women. In W.B. WALSH \& S.H. OsIPOW (Eds), Handbook of Vocational Psychology. Hillsdaie, N]: Erlbaum.

GinzBerg, E., GinsBurg, S.W., AXELrad, S. \& Herma, J.L. (1951). Occuparional Choice: an Approach to a General Theory. New York: Columbia University Press.

GotTRREDSON, L. (1981). Circumscription and compromise: a development theory of occupational aspirations. Foumal of Counseling Psychology, 28, 545-579.

Greenhaus, J.H., HaWkINS, B.L. \& BrenNeR, O.C. (1983). The impact of career exploration among undergraduate business students. Joumal of College Student Personnel, 24, 394-502.

Grotevant, H.D. (1987). Toward a process model of identity formation. Foumal of Adolescent Research, 2, 203-222.

Grotevant, H.D. \& CoOper, C.R (1985). Pattems of interaction in family relationships and the development of identity and role-taking skill in adolescence. Child Development, 56, 415-428.

GrotevaNT, H.D. \& COOPER, C.R. (1988). The role of family experience in career exploration: a life span perspective. In P. BALTES, R.H. LeRNER \& D. FeATHERMan (Eds), Life-Span Devdopment and Behavior (Vol. 8, pp. 231-258). Hillsdale, NJ: Erlbaum.

GroteVANT, H.D. \& DURRETT, M.E. (1980). Occupational knowledge and career development in adolescence. Foumal of Vocational Behavior, 17, 171-182.

HACKETT, G. \& BETZ, N.E. (1981). A self-efficacy approach to the career development of women. Foumal of Vocational Behavior, 18, 326-339.

HACKETT, G. \& BYARS, A.M. (1996). Social cognitive theory and the career development of African American women. Career Development Quarterly, 44, 322-340.

HARREN, V.A. (1979). A model of career decision-making for college students. foumal of Vocational Behavior, 14, 119-133.

HOLLAND, J.L. (1985). Making Vocational Choices: a Theory of Vocational Personalities and Work Environments (2nd edn). Englewood Cliffs, NJ: Prentice-Hall.

JEPSEN, D.A. (1984). The developmental perspective on vocational behavior: a review of theory and research. In D.S. BROWN \& R.W. LENT (Eds), Handbook of Counseling Psychology (pp. 178-215). New York: Wiley.

JORDAAN, J.P. (1963). Exploratory behavior: the formation of self and occupational concepts. In D.E. Super, R. Starishevsky, N. Matun \& J.P. Jordanan (Eds), Careet Development: Self-Concept Theory. New York: College Entrance Examination Board.

JORDAAN, J.P. (1974). Life stages as organizing modes of career development. In E. L. HERR (Ed.), Vocational Guidance and Human Development (pp. 263-295). Boston, MA: Houghton Mifflin. 


\section{Maria do Céu Taveira et al.}

JORESKOG, K.G. (1969). A general approach to confirmatory maximum likelihood factor analysis. Psychometrica, 34, 182-202.

JORESKOG, KG. (1977). Structural equation models in the social sciences: specification, estimation and testing. In P.R Krishnainh (Ed.), Applications of Statistics. Amsterdam: North Holland.

JORESKOG, K.G. \& SORBOM, D. (1989). LISREL VII: User's Reference Guide. Chicago: Scientific Software.

LENT, R.W. \& BRoWN, S.D. (1996). Social cognitive approach to career development: an overview. Carect Development Quarterty, 44, 310-321.

LENT, R.W., BROWN, S.D. \& HACKETT, G. (1994). Toward a unified social cognitive theory of career/academic interest, choice and performance. Journal of Vocational Behavior, 45, 79-122.

MrTCHEL, L.K. \& KRUMBOLTZ, J.D. (1990). Social leaming approach to career decision making: Krumbolz's theory. In D. BrowN, L Brooks \& Associates (Eds), Career Choice and Development: Applying Contemporary Theories to Practice (2nd edn) (pp. 145-196). San Francisco: Jossey-Bass.

PHW I IPS, S. (1992). Career counseling: choice and implementation. In S.D. BROWN \& R.W. LENT (Eds), Handbook of Counseling Psychology (2nd edn) (pp. 513-547). New York: Wiley.

Ruchardson, M.S. (1993). Work in people's lives: a location for counseling psychologists. foumal of Counseling Psychology, 40, 425-433.

SEARLE, S.R. (1971). Linear Models. New York: Wiley.

SPOKane, A.R (1991). Career Intervention. Englewood Cliffs, NJ: Prentice-Hall.

STUMPF, S.A. \& LOCKHART, M.C. (1987). Career exploration: work-role salience, work preferences, beliefs, and behavior. Foumal of Vocational Behavior, 30, 258-289.

STUMPF, S.A., COLARELU, S.M. \& HARTMAN, K (1983). Development of the career exploration survey (CES). foumal of Vocarional Behavior, 22, 191-226.

SUPER, D.E. (1957). The Psychology of Careers. New York: Harper \& Row.

SUPER, D.E. (1963). Vocational development in adolescents and early adulthood: tasks and behaviors. In D.E. SUPER, R StarushevskY, N. Matin \& J.P. Jordan, Careet Development: Self Concept Theory. New York: College Entrance Examination Board.

SUPER, D.E. (1990). A life-span, life-space approach to career development. In D. BROWN, L. Brooks \& Associates, Careet Choice and Development (2nd edn) (pp. 197-261). San Francisco: Jossey-Bass.

TABACHATCK, B.G. \& FmELL, L.S. (1989). Using Multivariale Staristics. New York: Harper \& Row.

Taveira, M.C., Nunes, J.M., Mesqutta, A., Rodriguez, M.L., Silva, C., Alves, C. \& Mirhazes, G. (1994). Avaliação das necessidades de educação vocacional de jovens: implicaçð̃es para o desenvolvimento de programas de exploração vocacional. In L. ALmeidA \& I. RuBEiro (Eds), Avalią̧ão Psicológica (2nd edn) (pp. 263-272). Braga: Apport.

TEEEman, D.V. (1961). Decision and vocational development: a paradigm and its implications. Personnel and Guidance Journal, 40, 15-21.

TIEDEMAN, D.V. \& O'HARA, R.P. (1963). Career Development: Choice and Adjustment. New York: College Entrance Examination Board.

VoNdRACEK, F.W., LeRner, R.M. \& Schurenberg, J.E. (1986). Career Development: a Life-Span, Developmental Approach. Hillsdale, NJ: Erlbaum.

ZuNker, V.G. (1994). Career Counseling: Applied Concopes of Life Planning (4th edn). Pacific Grove, CA: Brooks Cole.

(Accepted 28 Fanuary 1997) 